\title{
Masks Do More Than Protect Others During COVID-19: Reducing the Inoculum of SARS-CoV-2 to Protect the Wearer
}

\author{
Monica Gandhi, MD, $\mathrm{MPH}^{\top}{ }^{\mathrm{D}}$, Chris Beyrer, $\mathrm{MD}, \mathrm{MPH}^{2}$, and Eric Goosby, $\mathrm{MD}^{7}$
}

'Department of Medicine, Division of HIV, Infectious Diseases and Global Medicine, University of California, San Francisco (UCSF) San Francisco, CA, USA; ${ }^{2}$ Desmond M. Tutu Professor of Public Health and Human Rights, Johns Hopkins Bloomberg School of Public Health Baltimore, MD, USA.

\begin{abstract}
Although the benefit of population-level public facial masking to protect others during the COVID-19 pandemic has received a great deal of attention, we discuss for one of the first times the hypothesis that universal masking reduces the "inoculum" or dose of the virus for the maskwearer, leading to more mild and asymptomatic infection manifestations. Masks, depending on type, filter out the majority of viral particles, but not all. We first discuss the near-century-old literature around the viral inoculum and severity of disease (conceptualized as the LD50 or lethal dose of the virus). We include examples of rising rates of asymptomatic infection with population-level masking, including in closed settings (e.g., cruise ships) with and without universal masking. Asymptomatic infections may be harmful for spread but could actually be beneficial if they lead to higher rates of exposure. Exposing society to SARS-CoV-2 without the unacceptable consequences of severe illness with public masking could lead to greater community-level immunity and slower spread as we await a vaccine. This theory of viral inoculum and mild or asymptomatic disease with SARS-CoV-2 in light of population-level masking has received little attention so this is one of the first perspectives to discuss the evidence supporting this theory.
\end{abstract}

J Gen Intern Med 35(10):3063-6

DOI: $10.1007 / \mathrm{s} 11606-020-06067-8$

(๑) Society of General Internal Medicine 2020

$\mathrm{T}$ his perspective outlines a unique angle on why universal public masking during the COVID-19 pandemic should be one of the most important pillars of disease control. Our theory is based on the likelihood of masking reducing the viral inoculum to which the mask-wearer is exposed, leading to higher rates of mild or asymptomatic infection with COVID19. No prior perspective has specifically focused on this link between population-level facial masking, the viral inoculum, and increasing rates of asymptomatic infection with SARSCoV-2.

Received June 22, 2020

Accepted July 15, 2020

Published online July 31, 2020
On April 3, 2020, the Centers for Disease Control and Prevention issued recommendations on wearing cloth face coverings by the public to reduce community spread. ${ }^{1}$ The World Health Organization did not recommend populationlevel face masking in April, ${ }^{2}$ but changed their guidance on June $5,2020,{ }^{3}$ when the extent of transmission from presymptomatic or even asymptomatic individuals was clear. ${ }^{4,5}$ One recent model showed that population-level masking is one of the most efficacious interventions to reduce further spread of SARS-CoV-2, allowing for less-stringent lock-down requirements in countries adopting this strategy. ${ }^{6}$ Countries worldwide have had a range of responses to the recommendation on universal masking, with many countries (and US states) ${ }^{7}$ issuing mandates and enforcement strategies. ${ }^{8}$ Countries accustomed to universal population-level masking since the SARS epidemic in 2003 adopted the intervention more readily. ${ }^{9}$

There are two likely reasons for the effectiveness of facial masks: The first - to prevent the spread of viral particles from asymptomatic individuals to others - has received a great deal of attention. ${ }^{10,11}$ However, the second theory-that reducing the inoculum of virus to which a mask-wearer is exposed will result in milder disease ${ }^{12-27}$ _has received less attention and is the focus of our perspective which compiles virologic, epidemiologic and ecologic evidence.

Masks, depending on the material and design, filter out a majority of viral particles, but not all. ${ }^{28}$ The theory that exposure to a lower inoculum or dose of any virus (whether respiratory, gastrointestinal or sexually transmitted) can make subsequent illness far less likely to be severe ${ }^{12-27}$ has been propounded for some time. Indeed, the concept of the 50\% lethal dose (LD50), the virus dose at which $50 \%$ of exposed hosts die, determined via controlled experiments in which a range of exposure doses are administered to animals to calculate a dose-mortality curve, was first described in $1938 .{ }^{18}$ Other studies have examined the LD50 - or the dose that leads to severe disease or death-for a variety of viruses in hosts or animal models. ${ }^{17,}$ 21, 29-34

These studies have limitations, since experiments to examine the dose of virus to achieve its LD50 have necessarily not been conducted in humans. Studies to experimentally examine the dose of virus associated with different levels of diseases 

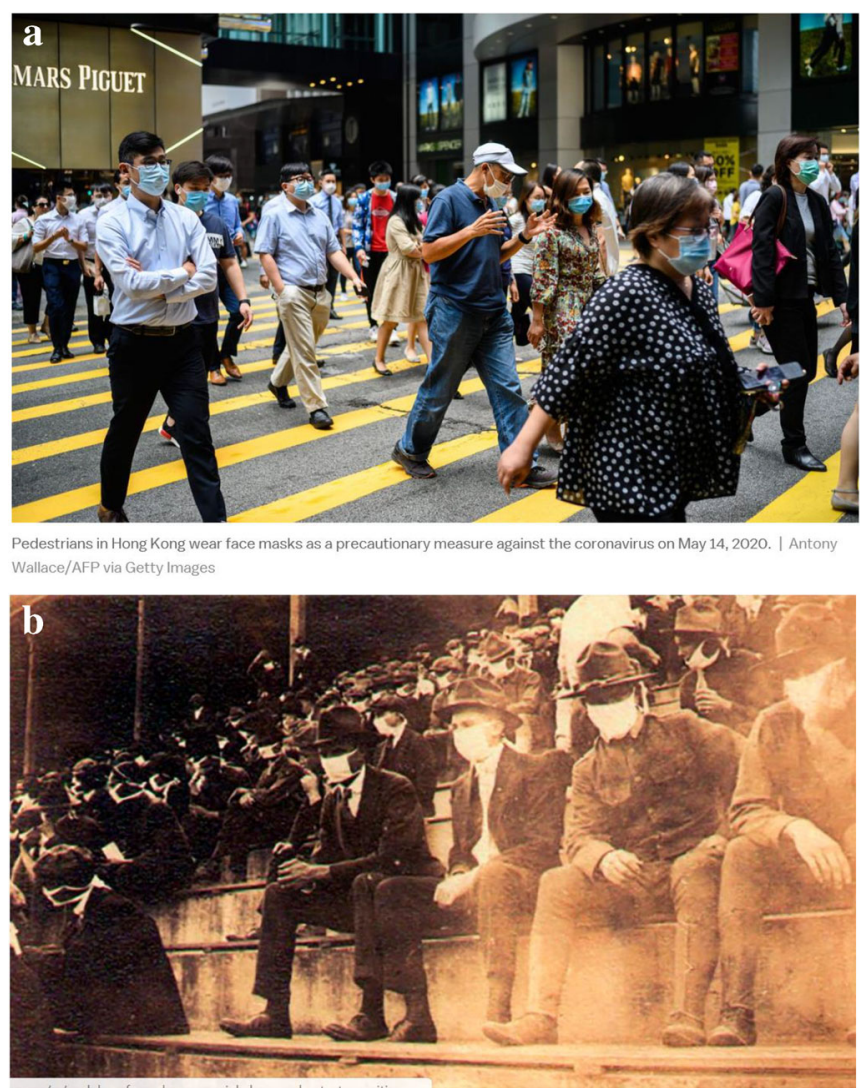

Figure 1 a Busy Hong Kong Street on May 14, 2020, demonstrating universal public masking, ${ }^{44}$ only five deaths reported in Hong Kong from COVID-19. b Georgia Tech football game with fans wearing masks packed in a campus stadium in the midst of the 1918 influenza pandemic. ${ }^{45}$

severity in humans have been limited to non-lethal viruses. In one experiment in preparation for vaccine development, healthy human volunteers exposed to different doses of wildtype influenza A virus developed more severe symptoms at higher inocula of administered virus. ${ }^{34}$ Giving SARS-CoV-2 in a range of doses to humans experimentally would be unethical, but an animal model has tested this theory of masking attenuating disease severity. In a frequently cited study showing that hamsters are less likely to contract SARS-CoV-2 infection with a surgical mask partition, those hamsters that did contract COVID-19 with simulated masking had milder manifestations of infection. ${ }^{27}$

Increasing rates of asymptomatic and mild infection with COVID-19 have been seen over time during the pandemic in settings adopting population-level masking. A systematic review of earlier studies, before facial masking was widely practiced, placed the proportion of asymptomatic infection with SARS-CoV-2 at $15 \% .{ }^{35}$ A more recent narrative review of 16 different studies estimated the rate of asymptomatic infection at $40-45 \%{ }^{36}$ The CDC has now (since article submission) also placed the rate of asymptomatic infection at $40 \%$ - the reference is as follows and could this new reference be placed here: "Centers for Disease Control and Prevention (CDC). COVID-19 Pandemic Planning Scenarios. July 10, 2020. https://www.cdc.gov/coronavirus/2019-ncov/hcp/planning-scenarios.html." Closed settings, such as cruise ships, can be particularly illustrative when examining phenotypes associated with SARS-CoV-2. For example, one of the earliest estimates of the rate of asymptomatic infection due to SARSCoV-2 was in the $20 \%$ range from a report of a COVID-19 outbreak on the Diamond Princess cruise ship. ${ }^{37}$ In a more recent report from a different cruise ship outbreak, all passengers were issued surgical masks and all staff provided N95 masks after the initial case of COVID-19 on the ship was detected. ${ }^{38}$ In this closed setting with masking, where 128 of 217 passengers and staff eventually tested positive for SARSCoV-2 via RT-PCR, the majority of infected patients on the ship (81\%) remained asymptomatic, ${ }^{38}$ compared with $18 \%$ in the cruise ship outbreak without masking. ${ }^{37}$

A report from a pediatric hemodialysis unit in Indiana, where all patients and staff were masked, demonstrated that staff rapidly developed antibodies to SARS-CoV-2 after exposure to a single symptomatic patient with COVID-19. In the setting of masking, however, none of the new infections was symptomatic. ${ }^{39}$ And in a recent outbreak in a seafood processing plant in Oregon where all workers were issued masks each day at work, the rate of asymptomatic infection among the 124 infected was $95 \% .^{40,41}$ An outbreak in a Tyson chicken plant in Arkansas with masking also showed a 95\% asymptomatic rate of infection. ${ }^{42,43}$

One model showed a correlation between population-level masking and number of COVID-19 cases in various countries, but an even stronger correlation with suppression of COVIDrelated death rates. ${ }^{9}$ However, it should be acknowledged that 
this model could not account for all confounders that led to such low death rates in the regions examined. This group showed that, if $80 \%$ of the population wears a moderately effective mask, nearly half of the projected deaths over the next two months could be prevented. ${ }^{9}$ Countries accustomed to masking since the 2003 SARS-CoV pandemic, including Japan, Hong Kong (Fig. 1a), ${ }^{44}$ Taiwan, Thailand, South Korea, and Singapore, ${ }^{9}$ and those who newly embraced masking early on in the COVID-19 pandemic, such as the Czech Republic, ${ }^{46}$ have fared well in terms of rates of severe illness and death. Indeed, even when cases have resurged in these areas with population-based masking upon re-opening (e.g., South Korea, Singapore, Hong Kong, Taiwan), the casefatality rate has remained low, ${ }^{47}$ which is suggestive of this viral inoculum theory.

Although asymptomatic infection can be problematic in terms of increasing spread, ${ }^{4}$ it can also be beneficial. ${ }^{14}$ Higher rates of asymptomatic infection with SARS-CoV-2 lead to higher rates of exposure, as was seen with antibody testing campaigns in Japan ${ }^{48}$ or the surveillance study in the pediatric hemodialysis unit in Indiana. ${ }^{39}$ Exposing society to SARSCoV-2 without the unacceptable consequences of severe illness could lead to greater community-level immunity ${ }^{49}$ and slow down spread as we await a vaccine. However, the level of effective antibody and $\mathrm{T}$ cell immune responses to different manifestations of COVID-19 has not yet been determined. Monitoring for upticks in illness, not asymptomatic cases, could herald a need to re-enforce more stringent social distancing measures in a society which has adopted universal public masking going forward.

For this particular pillar of pandemic control to work in the USA, leading politicians will need to endorse and model mask-wearing. The USA has embraced universal public masking before, during the 1918 Spanish influenza pandemic (Fig. 1b), ${ }^{45}$ but the CDC recommendation made on April 3, 2020, for public masking due to COVID-19 has been unevenly followed. ${ }^{7}$ The efforts to preserve life must be balanced against the catastrophic consequences of shutting down economies, which ultimately will lead to more suffering, poverty, and death than the virus itself, especially for the working poor. Although universal public masking can certainly protect others, the "inoculum" theory argues for a major protective effect for the individual and will allow for the preservation of life, along with other COVID-19 control measures, as society re-opens. This perspective puts forth another advantage of population-level facial masking for pandemic control with SARS-CoV-2 based on an old but enduring theory ${ }^{18}$ regarding viral inoculum, clinical manifestations in the host, and protection.

Acknowledgments: We would like to acknowledge all the brave health care workers fighting COVID-19.

Corresponding Author: Monica Gandhi, MD, MPH; Department of Medicine, Division of HIV, Infectious Diseases and Global Medicine,
University of California, San Francisco (UCSF) San Francisco, CA, USA (e-mail: monica.gandhi@ucsf.edu).

Funding Information Funding source for this perspective: NIAID/ NIH 2 P3O AIO27763 (Gandhi, P.I.)

\section{Compliance with Ethical Standards:}

Conflict of Interest: The authors declare that they do not have a conflict of interest.

\section{REFERENCES}

1. Centers for Disease Control and Prevention. Regarding the Use of Cloth Face Coverings, Especially in Areas of Significant Community-Based Transmission. April 3, 2020. https://www.cdc.gov/coronavirus/2019ncov/prevent-getting-sick/cloth-face-cover.html. Accessed June 22, 2020

2. World Health Organization. Advice on the use of masks in the context of COVID-19. Interim guidance. 6 April 2020. Accessible at: https://apps. who.int/iris/handle/10665/331693. Accessed June 22, 2020

3. World Health Organization. Advice on the use of masks in the context of COVID-19, Interim guidance, 5 June 2020. Accessible at: https://www. who.int/publications/i/item/advice-on-the-use-of-masks-in-the-community-during-home-care-and-in-healthcare-settings-in-the-context-ofthe-novel-coronavirus-(2019-ncov)-outbreak. Accessed June 22, 2020

4. Gandhi M, Yokoe DS, Havlir DV. Asymptomatic Transmission, the Achilles' Heel of Current Strategies to Control Covid-19. N Engl J Med 2020; 382:2158-2160

5. He $\mathbf{X}$, Lau EHY, Wu $\mathbf{P}$, et al. Temporal dynamics in viral shedding and transmissibility of COVID-19. Nat Med 2020; 26(5): 672-5.

6. Stutt R, Retkute R, Bradley M, Gilligan CA, Colvin J. A modelling framework to assess the likely effectiveness of facemasks in combination with 'lock-down' in managing the COVID-19 pandemic. Proc R Soc 2020, https://doi.org/10.1098/rspa.2020.0376.

7. Lyu w, Wehby GL. Community Use Of Face Masks And COVID-19: Evidence From A Natural Experiment Of State Mandates In The US. Health Aff (Millwood) 2020: 101377hlthaff202000818. Accessed June 22, 2020

8. 3 Massachusetts cities to begin issuing fines for people not wearing face masks in public. 7 News Boston. April 29, 2020. Acccessible at: https:// whdh.com/news/3-massachusetts-cities-to-begin-issuing-fines-for-people-not-wearing-face-masks-in-public/. Accessed June 22, 2020

9. Kai D. et al. Universal Masking is Urgent in the COVID-19 Pandemic: SEIR and Agent Based Models, Empirical Validation, Policy Recommendations. April 22, 2020. Accessible at: https://arxiv.org/pdf/2004. 13553.pdf. Accessed June 22, 2020

10. Gandhi M, Havlir D. The Time for Universal Masking of the Public for Coronavirus Disease 2019 Is Now. Open Forum Infect Dis 2020; 7(4): ofaal31.

11. Eikenberry SE, Mancuso M, Iboi E, et al. To mask or not to mask: Modeling the potential for face mask use by the general public to curtail the COVID-19 pandemic. Infect Dis Model 2020; 5: 293-308.

12. Handel A, Li Y, McKay B, Pawelek KA, Zarnitsyna V, Antia R. Exploring the impact of inoculum dose on host immunity and morbidity to inform model-based vaccine design. PLoS Comput Biol 2018; 14(10): e1006505.

13. Miller DS, Kok T, Li P. The virus inoculum volume influences outcome of influenza A infection in mice. Lab Anim 2013; 47(1): 74-7.

14. Raoult D, Zumla A, Locatelli F, Ippolito G, Kroemer G. Coronavirus infections: Epidemiological, clinical and immunological features and hypotheses. Cell Stress 2020; 4(4): 66-75.

15. Yang $\mathbf{R}$, Gui $\mathbf{X}$, Xiong $\mathbf{Y}$. Comparison of Clinical Characteristics of Patients with Asymptomatic vs Symptomatic Coronavirus Disease 2019 in Wuhan, China, JAMA Netw Open 2020; 3(5): e2010182.

16. Chan JF, Zhang AJ, Yuan S, et al. Simulation of the clinical and pathological manifestations of Coronavirus Disease 2019 (COVID-19) in golden Syrian hamster model: implications for disease pathogenesis and transmissibility. Clin Infect Dis 2020.

17. McKenney DG, Kurath G, Wargo AR. Characterization of infectious dose and lethal dose of two strains of infectious hematopoietic necrosis virus (IHNV). Virus Res 2016; 214: 80-9.

18. Reed LJ, Muench H. A simple method of estimating fifty per cent endpoints. The American Journal of Hygiene. 1938;27(3):493-7.

19. Casadevall A. The Pathogenic Potential of a Microbe. mSphere 2017; 2(1). 
20. Bouvier NM, Lowen AC. Animal Models for Influenza Virus Pathogenesis and Transmission. Viruses 2010; 2(8): 1530-63.

21. Tao X, Garron T, Agrawal AS, et al. Characterization and Demonstration of the Value of a Lethal Mouse Model of Middle East Respiratory Syndrome Coronavirus Infection and Disease. J Virol 2016; 90(1): 57-67.

22. Gralinski LE, Ferris MT, Aylor DL, Whitmore AC, Green R, Frieman MB, et al. Genome Wide Identification of SARS-CoV Susceptibility Loci Using the Collaborative Cross. PLoS Genet. 2015;11(10):e1005504. .

23. Roberts A, Deming D, Paddock CD, et al. A mouse-adapted SARScoronavirus causes disease and mortality in BALB/c mice. PLoS Pathog 2007; 3(1): e5.

24. Subbarao K, McAuliffe $\mathbf{J}$, Vogel $\mathbf{L}$, et al. Prior infection and passive transfer of neutralizing antibody prevent replication of severe acute respiratory syndrome coronavirus in the respiratory tract of mice. $J$ Virol 2004; 78(7): 3572-7

25. Virlogeux V, Fang VJ, Wu JT, et al. Brief Report: Incubation Period Duration and Severity of Clinical Disease Following Severe Acute Respiratory Syndrome Coronavirus Infection. Epidemiology 2015; 26(5): 666-9.

26. Davis N. Who is most at risk of contracting coronavirus? The Guardian2020 [Last accessed 2020-06-06]; Available from: https://www. theguardian.com/world/2020/feb/21/who-is-most-at-risk-ofcontracting-coronavirus. Accessed June 22, 2020

27. Chan JF, Yuan S, Zhang AJ, et al. Surgical mask partition reduces the risk of non-contact transmission in a golden Syrian hamster model for Coronavirus Disease 2019 (COVID-19). Clin Infect Dis 2020. https://doi. org/10.1093/cid/ciaa644

28. Smereka J, Ruetzler K, Szarpak L, Filipiak KJ, Jaguszewski M. Role of mask/respirator protection against SARS-CoV-2. Anesth Analg 2020. Accessed June 22, 2020

29. Engelking HM, Leong JC. The glycoprotein of infectious hematopoietic necrosis virus elicits neutralizing antibody and protective responses. Virus Res 1989; 13(3): 213-30.

30. S.E. LaPatra, J.L. Fryer, J.S. Rohovec. Virulence comparison of different electropherotypes of infectious hematopoietic necrosis virus. Dis. Aquat. Org., 16 (1993), pp. 115-1.

31. Kim R, Faisal M. Comparative susceptibility of representative Great Lakes fish species to the North American viral hemorrhagic septicemia virus Sublineage IVb. Dis Aquat Organ 2010; 91(1): 23-34.

32. Brown JD, Stallknecht DE, Berghaus RD, Swayne DE. Infectious and lethal doses of H5N1 highly pathogenic avian influenza virus for house sparrows (Passer domesticus) and rock pigeons (Columbia livia). $J$ Vet Diagn Invest 2009; 21(4): 437-45.

33. S.E. LaPatra, J.L. Fryer, J.S. Rohovec. Virulence comparison of different electropherotypes of infectious hematopoietic necrosis virus. Dis. Aquat. Org., 16 (1993), pp. 115- 120.

34. Memoli MJ, Czajkowski L, Reed S, et al. Validation of the wild-type influenza A human challenge model H1N1pdMIST: an A(H1N1)pdm09 dose-finding investigational new drug study. Clin Infect Dis 2015; 60(5): 693-702.

35. Buitrago-Garcia D et al. The role of asymptomatic SARS-CoV-2 infections: rapid living systematic review and meta-analysis. May 24, 2020. Accessible at: https://doi.org/10.1101/2020.04.25.20079103.this. Accessed June 22, 2020

36. Oran DP, Topol EJ. Prevalence of Asymptomatic SARS-CoV-2 Infection: A Narrative Review. Ann Intern Med 2020. https://doi.org/10.7326/M203012
37. Mizumoto $\mathbf{K}$, Kagaya $\mathbf{K}$, Zarebski A, Chowell G. Estimating the asymptomatic proportion of coronavirus disease 2019 (COVID-19) cases on board the Diamond Princess cruise ship, Yokohama, Japan, 2020. Euro Surveill 2020; 25(10).

38. Ing AJ, Cocks C, Green JP. COVID-19: in the footsteps of Ernest Shackleton. BMJ Thorax. https://doi.org/10.1136/thoraxjnl-2020215091.

39. Hains DS, Schwaderer AL, Carroll AE, et al. Asymptomatic Seroconversion of Immunoglobulins to SARS-CoV-2 in a Pediatric Dialysis Unit. JAMA 2020;323(23):2424-2425

40. Cline S. Cases at seafood plant cause spike in Oregon COVID numbers. The Associated Press. June 9, 2020. Accessible at: https://www. newsbreak.com/oregon/salem/news/OPI8ZP7b/cases-at-seafood-plantcause-spike-in-oregon-covid-numbers. Accessed June 22, 2020

41. 124 COVID-19 cases reported at Pacific Seafood in Newport. KGW. June 8, 2020. Newport, Oregon. Accessible at: https://www.kgw.com/ article/news/health/coronavirus/pacific-seafood-outbreak-increases-to124-covid-19-cases /283-ffeb0712-76c0-45ea-b6c8-b7644def0ad 1. Accessed June 22, 2020

42. Hundreds test positive at Tyson Foods plant in Arkansas as China suspends imports. June 22, 2020. Associated Press. https://www. latimes.com/world-nation/story/2020-06-22/hundreds-test-positive-coronavirus-tyson-foods-plant-arkansas.

43. San Francisco Department of Public Health. Order of the Health Officer of the City and County of San Francisco Generally Requiring Members of the Public and Workers to Wear Face Coverings. April 17, 2020. Accessible at: https://www.sfdph.org/dph/alerts/files/OrderNoC19-12RequiringFaceCovering-04172020.pdf. Accessed June 22, 2020

44. Ward A. How masks helped Hong Kong control the coronavirus. Vox. May 18, 2020. Accessible at: https://www.vox.com/2020/5/18/ 21262273/coronavirus-hong-kong-masks-deaths-new-york. Accessed June 22, 2020

45. Niemietz B. Photo of 1918 college football fans wearing face masks points to the past and future. New York Daily News. May 25, 2020. Accessible at: https://www.nydailynews.com/coronavirus/ny-photo-mask-georgiate ch - 1918 - pandemic - flu - coronavirus - 20200525 fbkqrf6tajgf7plck2emfjdjvi-story.html. Accessed June 22, 2020

46. Czechs get to work making masks after government decree. The Guardian. March 30, 2020. Accessible at: https://www.theguardian. com/world/2020/mar/30/czechs-get-to-work-making-masks-after-government-decree-coronavirus. Accessed June 22, 2020

47. World Health Organization (WHO) Coronavirus Disease (COVID-19) Dashboard. June 19, 2020 (updated daily). Accessible at: https:// covid19.who.int/. Accessed June 22, 2020

48. Doi $\mathbf{A}$ et al. Seroprevalence of novel coronavirus disease (COVID-19) in Kobe, Japan. May 1, 2020. medRxiv preprint https://doi.org/10.1101/ 2020.04.26.20079822. Accessed June 22, 2020

49. Leslie M. T cells found in COVID-19 patients 'bode well' for long-term immunity. Science. May. 14, 2020. https://www.sciencemag.org/news/ 2020/05/t-cells-found-covid-19-patients-bode-well-long-term-immunity?utm. Accessed June 22, 2020

Publisher's Note: Springer Nature remains neutral with regard to jurisdictional claims in published maps and institutional affiliations. 